\title{
Employers' perception of breastfeeding practice of employed mothers in Addis Ababa, Ethiopia: a qualitative study
}

Firmaye Bogale Wolde ( $\nabla$ fbfbogale93@gmail.com )

Ethiopian Public Health Institute https://orcid.org/0000-0003-2987-8872

Jemal Haidar Ali

Addis Ababa University School of Public Health

Yalemwork Getnet Mengistu

Addis Ababa University School of Public Health

\section{Research}

Keywords: Employer, Breastfeeding, Work environment, Mother-friendly, Employed mothers

Posted Date: May 14th, 2020

DOI: https://doi.org/10.21203/rs.2.22490/v2

License: (c) (i) This work is licensed under a Creative Commons Attribution 4.0 International License.

Read Full License 


\section{Abstract}

Background: The universal importance of breastfeeding and human milk are demonstrated by different researches but despite the importance only $37 \%$ of children are exclusively breastfed worldwide. Women employment is one way of ensuring women's empowerment but it is also one of the commonly mentioned factors contributing for the low prevalence of breastfeeding. Hence, there needs to be a conducive work environment that accommodates maternal needs not to fall back from empowerment and to improve breastfeeding practice. There are not many studies that focus on work environment in relation with employers' experience and their perception of breastfeeding of employed mothers. Therefore this study aims to explore employers' experience and perception of employed mothers' breastfeeding experience in different working environments in Addis Ababa, Ethiopia.

Methods: A descriptive phenomenology strategy was employed in this study and purposive sampling technique was used to recruit study participants. Data was collected from 10 employers from private, governmental and non-governmental institutions through an in-depth interview. Thematic data analysis was performed where collected data was organized, coded and categorized into themes to give meaningful contributions to answering the research questions.

Results: Understanding breastfeeding, current maternity leave, perception of breastfeeding supporting conditions and mother-friendly work environment were the themes generated after analysis. Almost all employers in this study recognized the importance of breastfeeding despite the different work environments they worked in and they also acknowledged the importance of making working environment mother-friendly for stability and motivation of employed mothers.

Conclusions: Providing mothers with a friendly environment is understood as a positive thing by employers. The current maternity leave of three months has low acceptance and both onsite child care center and six-month maternity leave are believed to help in creating a mother-friendly work environment despite their pros and cons.

\section{Background}

The universal importance of breastfeeding and human milk are demonstrated by different researches indicating it's nutritional, immunologic, developmental, psychological, cognitive, socio-economic, and health significance [1-3]. The World Health Organization (WHO) and United Nations Children's Fund (UNICEF) recommend exclusive breastfeeding for the first six months of life and continued breastfeeding to the age of two and beyond with appropriate and sufficient complementary foods, but despite the importance and international recommendations only $37 \%$ of children are exclusively breastfed worldwide [4-6].

There are various contributing factors for this low prevalence of breastfeeding where maternal employment is one of the commonly mentioned factors [7-10]. With regards to employment of mothers, factors like employers' knowledge and attitude towards breastfeeding, and support provided at the 
workplace are listed as some aspects that affect breastfeeding [11]. Subsequently, studies in Ethiopia show breastfeeding prevalence of employed mothers is lower than unemployed mothers $[12,13]$.

Women employment is one way of ensuring women's empowerment but there needs to be a conducive work environment that accommodates maternal needs not to fall back from empowerment. The possibility of breastfeeding must be ensured for all mothers by viewing breastfeeding practice as a result of the combined effort of government, work environment, family and community rather than putting it as a one-woman job [14].

There are different studies on breastfeeding experience of employed mothers but there are not many that focus on employers' experience and perception of breastfeeding of employed mothers in different working environments in the Ethiopian setting.

Exploring this issue will not only show employers' experience but will be a standing point to understand employers' view and find suiting conditions for better breastfeeding practice.

Therefore, this study aims to explore employers' experience and perception of employed mothers' breastfeeding experience in different working environments in Addis Ababa, Ethiopia. Accordingly, this study will mainly try to answer the questions; what does the experience of employers working with employed mothers who breastfeed look like? and what is the perception of employers towards breastfeeding of employed mothers and supporting conditions in the workplace?

\section{Methods}

\section{Design}

A descriptive Phenomenology strategy was employed in this study where studying a small number of subjects through extensive engagement to develop patterns and relationships of meaning is done as described in Creswell research design 3rd edition [15].

\section{Participants}

The study population in this study included employers and personnel from major stakeholders responsible for issues related to breastfeeding. This study included 10 employers from private, governmental and non-governmental institutions.

Purposive sampling technique was used to recruit study participants where human resource officers or directors of institutions in each organization helped to identify eligible participants in the organizations. Participants who were in an employer position and were responsible and had the authority to decide on issues regarding breastfeeding in the organizations under study were included.

\section{Data collection}


Data collection was done through in-depth interview by using an interview guide that contained semistructured and a few open-ended questions to have a high degree of flexibility.

Each interview question had a single core question that permitted participants to express what they felt while maintaining a central frame of inquiry. The interview had questions on general knowledge of employers on breastfeeding, the experience of employers on working with breastfeeding mothers, knowledge and perception on mother-friendly work environment and experience with regards to supporting conditions for breastfeeding in the workplace.

The interview guide was improved by arranging question orders, clarifying questions and adding missing probes by doing three pretest interviews during which time wording and some question order changes were done. Some missing probes were also added after the first two interviews which were found to bring in more information. Questions were modified but not changed once the interview was started. All interviews were conducted by the principal investigator (FB) who worked in a governmental organization but did not have experience of acting as an employer of breastfeeding mothers.

The date, time, and place of each interview were arranged following what was most favorable and comfortable for the participants. All the interviews were audiotaped with the participant's consent and the interviews took an average of an hour. Informed consent was taken before each interview where participants were informed about the purpose, procedures, benefits, risks and the right of the respondents to refuse to respond for a few or all of the questions.

Data were collected from employers who met the inclusion criteria from Dec 2016-May 2017 in Addis Ababa the capital city of Ethiopia. Data were collected until information saturation was attained.

\section{Data analysis}

Thematic data analysis was performed to describe and compare general statements as relationships and themes present on the data according to the method of analysis described by Kleiman [16].

The interviews of this study were digitally recorded, transcribed verbatim and translated. The first stage of data analysis involved reading and re-reading each transcript and listening to the audio recording.

Initial coding was done in the second stage by reading the transcript in-depth and making note of anything important and paying attention to where and how patterns occurred. Thirdly codes were categorized into themes followed by searching for connections and meaning of emergent themes. The final stage involved generating clear definitions of each theme and their meaningful contributions to answering the research question.

During data collection respondent validation was done by restating and paraphrasing information for respondents to determine the accuracy, and participants were also revisited for transcript review before data analysis which gave better clarity on the data. Reliability was ensured by trying to avoid leading questions and all transcripts were cross-checked with the oral discourse for consistency, and transcripts 
and codes were constantly compared with the data to prevent drift of definition of codes [17]. The analysis was done manually and rigor was enhanced through regular discussions between authors who read all interview transcripts, counter checked the transcripts, coded the data and agreed on the emerging themes by going through the data.

\section{Operational definition}

Employer - Person responsible, directly or indirectly, for decisions on breastfeeding issues of an employed breastfeeding mother and supporting conditions provided.

Supporting condition at work- Refers to working condition that has provisions to enable employees to meet both their family and work commitments; in this study, it is represented by working conditions that have either onsite child care center or that provides six months of maternity leave.

\section{Results}

\section{Employers' demographic characteristics}

Table 1- Employers' basic characteristics, Addis Ababa, Ethiopia, 2017

\section{Employers characteristics}

\begin{tabular}{|c|c|c|c|c|}
\hline No & Code & Sex & Occupation & Organization \\
\hline 1 & EN & $\mathrm{F}$ & Human resource coordinator & Governmental Health Institution \\
\hline 2 & EN & M & Health department head & Governmental Education Institute \\
\hline 3 & EN & M & Human resource coordinator & Private Insurance Company \\
\hline 1 & $\mathrm{EO}$ & $\mathrm{F}$ & Women's affair officer & State Enterprise (Governmental) \\
\hline j & $\mathrm{EO}$ & $\mathrm{F}$ & Daycare coordinator & Private Technology Group \\
\hline j & $\mathrm{EO}$ & $\mathrm{F}$ & Manpower corporate director & Private Technology Group \\
\hline 7 & ES & M & $\begin{array}{l}\text { Health and nutrition department } \\
\text { coordinator }\end{array}$ & International NGO \\
\hline 3 & Esh & $\mathrm{F}$ & Child support \& inspection director & $\begin{array}{l}\text { Bureau of Women's And Youth Affair } \\
\text { (Governmental) }\end{array}$ \\
\hline 9 & Esh & $\mathrm{F}$ & Women's affair bureau director & $\begin{array}{l}\text { Bureau of Women's And Youth Affair } \\
\text { (Governmental) }\end{array}$ \\
\hline 10 & Esh & $\mathrm{F}$ & $\mathrm{MCH}$ and nutrition department coordinator & Federal Ministry of Health \\
\hline
\end{tabular}


EN- Employers from institution that has neither onsite childcare center nor six-month maternity leave.

EO- Employers from institution that has onsite childcare center.

ES- Employers from institution that gives six-month maternity leave.

Esh- Employers from stakeholder bureau.

Three male and seven female employers who came from range of positions that made them responsible for issues of employed mothers, breastfeeding and supporting conditions in the work place were involved in this study.

Three of the employers were from organizations that offer onsite child care center, one employer came from an organization that offers six-month maternity leave and three employers were from organizations with none of the two supporting conditions, and other three employers were from stakeholder bureaus.

Four themes were generated from the analysis of the data from interviews

i. Understanding breastfeeding.

ii. Current maternity leave.

iii. Perception of breastfeeding supporting conditions.

iv. Mother-friendly work environment

\section{Understanding breastfeeding}

\section{Duration of breastfeeding}

Almost all employers except one expressed that they believe six months exclusive breastfeeding is needed and should also be continued to two years. One employer, however, explained that with the current living situation and employment it is enough if mothers breastfeed up to the age of one.

"If you are asking me what I think, I say it's enough for an employed mother to breastfeed her baby only in the morning and night time to about a year; given the current living situation." En

\section{Breastfeeding benefits}

Employers described the benefit of breastfeeding majorly related to health, psychosocial wellbeing, and economic benefit.

"Breastfeeding has health benefits like a baby gets immunity from the first breast milk and breastfeeding doesn't need out of pocket-expense. Plus it improves psychosocial health by increasing the bond between mother and child." Es

They also expressed the impact of not breastfeeding on the development of children and the satisfaction of mothers. 
"In my opinion, if a mother doesn't breastfeed she will primarily lose mental satisfaction and she won't be able to care for her child which will hurt her child's growth." Es

\section{Current maternity leave}

Acceptance by employees and the effect of maternity leave

Regarding the acceptance of the current national law of maternity leave, which is three months, employers expressed that it is not accepted by employees because it doesn't consider the actual living situation and it hurts mothers' readiness for work. Additionally, it is explained that very few are in favor of the law because it contradicts with the recommendation of six months exclusive breastfeeding.

"Readiness to work is lesser among the workers who return from maternity leave. I'm afraid this is because it is not balanced with the workload they have which hurts the mothers." En

Employers also said mothers' restlessness, tiredness and being stressed are because of the shortness of the maternity leave given. They also explained that mothers come back because of the lack of options and that this affects the work.

"Even if a mother comes back to work she'll be restless and weak because she stays awake at night to breastfeed. Honestly speaking, mothers come back because they have no other option." En

\section{Implementation of maternity leave and coping mechanisms}

All participants explained that the three-month leave has two sections which are prenatal leave of one month and postnatal leave of two months duration but that there is a difference in the provision of the leave.

Most of the employers said that it cannot be amended in any way; even if a mother gave birth before taking any of her maternity leave she will only be given the two months postnatal leave. However, two respondents explained otherwise saying that a mother can take the whole three-month maternity leave after birth if she wants to.

"According to the current proclamation, maternity leave is given one month before and two months after birth. The law doesn't state the whole three months to be given after birth because it'll cause irregularities on work." Eo

According to the employers, annual leave is a solution mostly used to extend maternity leave and taking unofficial leave or break with the agreement of boss is also common.

"I try to help mothers with difficulties by arranging unofficial supports like coming in late to work and leaving early." En 
Another way that mothers try to cope with their problem as described by employers is taking leave without payment. They explained that mothers ask for this kind of leave when they have difficult situations and this kind of leave is granted according to the specific case a mother has. Employers also explained that this type of leave is generally not encouraged to prevent it from becoming a trend.

"Few mothers might not return to work after using both maternity and annual leave due to special cases like a child's health problem. Accordingly, mothers are given 'leave without payment' for one month or so. But we don't encourage this practice because if it becomes a trend it will grow in to a norm." En

\section{Perception of breastfeeding supporting conditions}

\section{$\underline{\text { View on onsite child care center }}$}

Onsite childcare center is discussed as one of the options to solve problems an employed woman faces as a mother. Participants discussed that presence of an onsite childcare center ensures women productivity, happiness at work and stability.

"When onsite childcare center is accessible mothers can do their job properly, become stable and happy." En

Participants explained the fact that mothers would not need to quit their jobs to raise their child if this center is accessible, which is what happens in most cases.

"The presence of a day care center will ease so many problems and mothers will not stay home or quit their job." En

There are some concerns presented by employers concerning an onsite childcare center which mainly are the difficulty it poses for an organization regarding space and related costs of hiring a baby sitter and fulfilling necessary facilities for the center. But despite these issues employers emphasized that the benefit outweighs the cost.

"As a facility what is thought as the cost of having an onsite child care center includes the space it takes and fulfilling all the important things to make it safe and comfortable for children. These children need someone to care for them which is additional cost to be covered by the facility." En

The other thing mentioned is the issue of convenience for women coming from far and the quality and consistency in the long run.

"We should insure that this place for children and mothers is permanent. The most common challenges are lack of space to build this center and making the service continuous with quality. Esh

Participants also explained that increment of female employee number might put extra pressure to the organization but it still has more advantage. 
The increment of female employees might bring changes like the need for hiring more baby sitters and expanding space because there will probably be more children. But the benefit of the center is still great." Eo

One of the challenges mentioned by employers in institution that has onsite childcare center is the difficulty of getting the mothers familiar with a programmed breastfeeding and care for children.

"One problem we faced was getting the mothers to breastfeed in the set out schedule. Mothers come just after finishing their leave and they are used to breastfeeding whenever they want which makes it hard for them to follow a schedule right away." Eo

View on six-month maternity leave

The other supporting condition discussed is six-month maternity leave. Employers discussed the contribution of six-month maternity leave in a sense that it increases productivity, focus on job and better breastfeeding trend.

"If a woman comes back to work after getting a six-month maternity leave she'll take care of major problems that she might face beforehand and she'll be stable at work." Es

Employers also expressed that it is a great opportunity for mothers to rehabilitate, especially for those on positions where a great deal of labor input is needed.

"I prefer the six-month leave because it helps mothers to recover because mothers in this factory work on machines all day. Imagine, these mothers had been pregnant for nine months and lost a lot of blood plus they breastfeed." Eo

The things raised as a concern by employers include the need and the difficulty of getting a replacement employee for the six months and the impact it has on the operation of the work.

"I think the issue here is the need for a person that fills in a mother's position when she is not around. This could mean additional arrangement of hiring replacement personnel." En

Another concern is related with difficulty of implementation because of lesser acceptance by private sectors and the probability of employers being inclined to hiring men over women.

"Private sectors might not be willing to implement six-month maternity leave and even if it they accept it as an obligation there will be high tendency of getting women out of the business using subtle reasons." Esh

\section{Mother-friendly work environment}

Understanding the meaning 
The employers understand the term mother-friendly environment as being an environment that accommodates mother's needs as a women and a mother by giving time to her child in addition to the her work. And they also said it should include an understanding staff and situations that are fitting to motherhood.

"The first thing is that the environment should give time to children in addition to the work. Secondly, I think there should be a well-rounded waiting place for children who are not old enough to get in to school." En

Employers also described that the environment should be beneficial to a mother and should fulfill her basic needs where she faces no problems because of pregnancy, being a women or a mother.

"Mother-friendly work environment is facilitating every vital thing for women during pregnancy and breastfeeding, like building a friendly place for mothers to breastfeed at work and making it functional." Esh

\section{Effect on mothers and breastfeeding}

Participants explained that creating a friendly work environment for mothers means in one way or another helping everyone else around her.

"A healthy mother can raise a healthy child and a healthy generation. That's why we need to push through as this is an issue helpful for all of us." En

Employers also emphasized on the fact that a friendly environment ensures mental satisfaction of women, makes them effective, stable and decreases absenteeism which in turn helps the organization.

"Creating a comfortable environment for a mother means creating a productive and stable employee. Mothers encounter different problems because of lack of enough care for their children that can be prevented by building a system that supports women and in turn decreases absenteeism." Eo

\section{Discussions}

The experience and perception of employers on mother-friendly work environment and breastfeeding of employed mothers in different work settings was explored by this study.

Employers in this study understood the importance of breastfeeding and the provision of women-friendly work environments with different views on the two supporting conditions, i.e. onsite child care center and six-month maternity leave.

All employers in this study explained the importance of breastfeeding for both children and mothers and almost all of them explained that a child should be breastfed for an exclusive six months and continue for two years. This is similarly explained by employers in other studies who pointed out the importance of 
breastfeeding for mothers and children and that mothers who breastfeed miss less work because of fewer episodes of child sickness $[18,19]$.

Employers in this study understand mother-friendly work environment as a place that accommodates the needs of a mother in a whole-rounded way and they agree on its importance which is also supported by another study in Ethiopia emphasizing the importance of putting breastfeeding-friendly work environment as a necessity comprising worksite daycare center [12]. However, despite the agreement, only a few employers have supporting conditions for breastfeeding employees.

It is seen in this study that employers have witnessed that mothers are stable and more productive when provided with a supporting condition at the workplace. This is similarly expressed in other studies that showed providing support at workplace improved job satisfaction, decreased turnover and reduced insurance costs [20-23].

According to this study, employers' preference for the type of supporting condition in the workplace differs based on their perception of advantage and disadvantage of the specific supporting condition in the workplace. This is consistent with the result of a systematic review which showed that all employers implement a breastfeeding support program that fits their company's budget and resources [24].

Ethiopia officially offers a three-month maternity leave which is often related to concerns of insufficient duration and non-uniform implementation, as explained by employers in this study. The presence of this non-uniform implementation has brought unofficial and differential treatment of employed mothers which could be contributing to the fact that most mothers do not get back to work just after three months which is also described by a study that conducted focus group discussion on maternity leave in Ethiopia [25]. Mothers either use their annual leave to lengthen their stay at home, or they sometimes bring sick leave to stay with their babies. This type of unexpectedly longer leave could bring more pressure on the work than planned maternity leave.

Regarding six-month maternity leave, employers raised the risk of extra cost and burden on work if several mothers go out on leave at the same time and stressed the related challenge to hire replacement employees just for six months. This can be linked with the concern of employers from stakeholder bureaus on how challenging it can be to implement the six-month maternity leave due to possible lack of acceptance by private sectors. Similarly, a study in India stated the potential abandonment of tasks in the workplace as well as a potential loss of some form of cash benefit that will be incurred because of lengthened leave [26].

Another supporting condition seen in this study is the onsite child care center. The concerns raised were the added cost of hiring babysitters, the need for extra space to build the center and ensuring the consistency of the service. These are also expressed as barriers in other studies where employers indicated that private places for nursing mothers could prove costly and raise budgetary issues $[18,26]$. In spite of these concerns, the majority of the employers described that an onsite childcare center is 
advantageous as it improved mothers' stability and productivity thereby decreasing employee turnover. Additionally, preplanning for these issues could solve them ahead of time.

Generally, employers with neither of the two supporting conditions and from the organization with sixmonth maternity leave were more inclined to having onsite childcare center in the workplace considering the anticipated negative impact of longer maternity leave on the operation of an organization.

\section{Conclusions}

Employers understood that providing a friendly work environment for employed mothers as beneficial. Even though both onsite child care center and six-months maternity leave have their advantages and disadvantages both are believed to help in creating a mother-friendly work environment better than the current three-month maternity leave.

Additionally, finding a conducive supporting condition by considering different working environments is needed. Further large scale quantitative researches are essential to substantiate the evidence generated from this study and look into the cost analysis of the different supporting conditions. It should also be taken into consideration that this study did not find more than one organization that provides a six-month maternity leave.

\section{List Of Abbreviations}

WHO- The world health organization

UNICEF- United Nations Children's Fund

NGO- Non-governmental organization

EN- Employers from institution that has neither onsite childcare center nor six-month maternity leave.

EO- Employers from institution that has onsite childcare center.

ES- Employers from institution that gives six-month maternity leave.

Esh- Employers from stakeholder bureau.

\section{Declarations}

\section{Ethics approval and consent to participate}

The study received ethical approval from the Research Ethical Committee of the School of Public Health, Addis Ababa University. Following this, written informed consent was obtained from the participants after the explanation of purpose, procedures, benefits, and risks of the study were made. All the interviews were done with strict privacy. 


\section{Consent for publication}

Not applicable

\section{Availability of data and materials}

The datasets used in this study are available from the corresponding author on reasonable request.

\section{Competing interests}

The authors declare that they have no competing interests

\section{Funding}

No funding is received for this study

\section{Authors' contributions}

FB initiated the research, wrote the research proposal, collected data, performed analysis, interpretation and wrote the manuscript with substantive inputs from JH and YG.

$\mathrm{JH}$ drafted the paper, wrote the research proposal, involved in analysis, interpretation and drafted the manuscript. YG involved in writing the research proposal, analysis and interpretation. All authors read and approved the final manuscript.

\section{Acknowledgment}

We would like to thank all participants in this study.

\section{References}

1. Anatolitou, F., Human milk benefits and breastfeeding. J PediatrNeonat Individual Med, 2012. 1(1): p. 11-8.

2. Alimoradi, F., et al., An Overview of Importance of Breastfeeding. J Compr Ped, 2014. 4.

3. Krol, K.M. and T. Grossmann, Psychological effects of breastfeeding on children and mothers. Bundesgesundheitsblatt - Gesundheitsforschung - Gesundheitsschutz, 2018. 61(8): p. 977-985.

4. UNICEF, Infant and young child feeding: programming guide., UNICEF, Editor. 2011: New York

5. Victora, C., et al., Breastfeeding in the 21st century: Epidemiology, mechanisms, and lifelong effect. The Lancet, 2016. 387: p. 475-490.

6. WHO/UNICEF, Global Strategy for Infant and Young Child Feeding. 2003.

7. Assembly, W.H., Global strategy for infant and young child feeding: the optimal duration of exclusive breastfeeding, W.H. Organization, Editor. 2001. 
8. Motee A and J. R, Importance of Exclusive Breastfeeding and Complementary Feeding among Infants. . Curr Res Nutr Food Sci 2014. 2(2).

9. Taddele, M., L. Abebe, and N. Fentahun, Exclusive breastfeeding and maternal employment in Ethiopia: A comparative cross-sectional study. International Journal of Food Sciences and Nutrition, 2014. 312: p. 497-503.

10. T, A., H. J, and H. D, Determinants of exclusive breastfeeding practices in Ethiopia Ethiopian Journal of Health Development, 2009. 23(1).

11. Su-Yung, T., Employee Perception of Breastfeeding-Friendly Support and Benefits as a Predictor of Intention to Use Breast-Pumping Breaks After Returning to Work Among Employed Mothers. . Breastfeed Med, 2014. 9(1): p. 16-23.

12. Tadesse, F., et al., Exclusive breastfeeding and maternal employment among mothers of infants from three to five months old in the Fafan zone, Somali regional state of Ethiopia: a comparative crosssectional study. . BMC Public Health, 2019. 19: p. 1015.

13. Chekol, D. and e. al., Exclusive breastfeeding and mothers' employment status in Gondar town, Northwest Ethiopia: a comparative cross-sectional study. Int Breastfeed J 2017. 12(27).

14. UNICEF, Let's make it work!: Breastfeeding in the workplace - Using Communication for Development to make breastfeeding possible among working mothers UNICEF, Editor. 2018: New York.

15. Creswell and J.W, Research Design: Qualitative, Quantitative, and Mixed Methods Approaches (3rd ed.). CA: Sage Publication, 2009.

16. Kleiman, S., Phenomenology: To wonder and search for meanings. Nurse Res, 2004. 11(4): p. 7-19.

17. Gibbs, G.R., The Nature of Qualitative Analysis in London: Sage Publications, Ltd. 2017.

18. Amin, R.M., Z.M. Sutan, and et. al, Work related determinants of breatsfeeding among employed mothers in Malaysia. Int Breastfeed J, 2011. 6(4).

19. Brown, A., S. Poag, and C. Kasprzycki, Exploring large employers' and small employers' knowledge, attitudes and practice on breastfeeding support in the work place. Journal of Human Lactation: SAGE open, 2001. 17(1): p. 39-46.

20. Abdulwadud, O. and M. Snow, Interventions in the workplace support breastfeeding for women in employment. Cochrane Database of Systematic Reviews, 2012. 10.

21. Mills, S.P., Workplace Lactation Programs: A Critical Element for Breastfeeding Mothers' Success. AAOHN Journal, 2009. 57(9): p. 227-231.

22. Kobala, J.A., Importance Of Creating Breastfeeding Facilities For Lactating Mothers At The Workplace: A Case Of Safaricom Kenya Limted. Semantic scholar, 2016.

23. Jantzer, A., J. Anderson, and R. Kuehl, Breastfeeding Support in the Workplace: The Relationships Among Breastfeeding Support, Work-Life Balance, and Job Satisfaction Journal of Human Lactation: SAGE open, 2017. 34(2).

24. Dinour, L. and J. Szaro, Employer-Based Programs to Support Breastfeeding Among Working Mothers: A Systematic Review. Breastfeeding Medicine, 2017. 12. 
25. Ketsela T, et al., Breastfeeding In Addis Ababa, Ethiopia: Results of a focus group study. . The Ethiopian Journal of Health Development (EJHD), 1996. 10(3).

26. Y., A., et al., The financing need for expanded maternity protection in Indonesia. International Breastfeeding Journal volume 2019. 14. 